\title{
Penentuan Rute Terpendek Jalur Distribusi Air Artesis Menggunakan Kruskal
}

\author{
Diah Ayu Retnani Wulandari' ${ }^{1}$, Fajrin Nurman Arifin ${ }^{2}$ \\ 1,2Fakultas Ilmu Komputer, Universitas Jember \\ Jl. Kalimantan No.37 Jember 68121 Indonesia, (0331)326935/(0331)326911 \\ diah.retnaniw@unej.ac.id,fajrin.pssi@unej.ac.id
}

\begin{abstract}
Water flow distribution to home residents from the artesian well is affected by infrastructure. The more houses that distributed makes decreased amount supply of artesian water in every house. the longer of pipe leight and many branches traversed makes decrease of water supply because there will be many possible pipeline leaks. The more pipes used make the more expensive infrastructure cost. This problem occurs in Jubung area. These problems is one variation of the minimum Spanning Tree problems. This problem can be solved by the shortest path optimization route. It uses network method by implementing graph theory through kruskal algorithm. The first step is determined the nodes and sides. Nodes represent house and the sides represents the connecting pipes between houses. Kruskal is chosen because the kruskal focuses on the side and the graph is incomplete. focus of this study is the length optimation of the connecting pipe that is represented by side. In the pipe infrastructure figure map is representing of an incomplete graph because there are several nodes that are not connected to all nodes because it is adapted to the contour of the land that is not possible traversed the pipe. The results is there are several paths that are changed, especially the side to connect between node 1-4, 4-12, 19-20, 21-6 dispensed because forming cycles. The result of this research is kruskal can make decreasing infrastrukture cost Rp.7.535.500 with length of 201,5 meter so can save Rp.4.401.000 from Rp Rp.11.936.500.
\end{abstract}

Keywords: kruskal, graf, network,minimum Spanning Tree,research operations

\begin{abstract}
Abstrak
Pendistribusian aliran air dari artesis sumur bor ke rumah penduduk dipengaruhi oleh infrastruktur. Semakin banyak rumah yang dialiri air maka semakin berkurangnya jumlah pasokan air tiap rumah. Semakin banyak pipa yang digunakan maka biaya infrastruktur semakin mahal. Permasalahan ini terjadi pada daerah Jubung. Permasalahan ini dapat diselesaikan melalui rekomendasi pengambilan keputusan optimasi pencarian jalur terpendek rute aliran air. Permasalahan ini termasuk permasalahan dalam minimum Spanning Tree. Penelitian ini menggunakan metode jaringan atau network pada bidang riset operasi dengan mengimplementasikan teori graf melalui algoritma kruskal. Langkah awal adalah menentukan node dan sisi. Node merepresentasikan rumah penduduk dan busur merepresentasikan pipa penghubung antar rumah. Algoritma kruskal dipilih karena algoritma kruskal berfokus pada sisi dan graf tidak lengkap. Fokus pada penelitian ini adalah optimasi panjang pipa penghubung yang direpresentasikan dengan sisi. Pada gambar peta infrastruktur pipa yang telah dibangun diketahui bahwa gambar tersebut merupakan graf tidak lengkap karena ada beberapa node yang tidak saling terhubung semua hal ini karena disesuaikan dengan kontur tanah yang tidak memungkinkan dilalui pipa. Hasil perhitungan ini adalah ada beberapa jalur yang dirubah terutama sisi penghubung node 1-4, 4-12, 19-20, 21-6 ditiadakan karena membentuk siklus. Hasil penggunaan pipa sebelum menggunakan algoritma kruskal adalah Rp.11.936.500 dengan panjang 340 meter dan setelah menggunakan algoritma kruskal adalah Rp.7.535.500 dengan panjang 201,5 meter sehingga dapat menghemat Rp.4.401.000.
\end{abstract}

Kata kunci: kruskal, graf, network,minimum Spanning Tree, riset operasi 


\section{PENDAHULUAN}

Air bor adalah air yang berasal dari pembuatan sumur dengan alat bantu bor untuk memperoleh sumber air artesis. Semakin cepatnya perkembangan penduduk dan semakin sempitnya lahan hijau menjadikan sumber air semakin sedikit [1][2]. Masalah air bersihpun semakin banyak ditemui. Pada saat ini air bersih yang diperoleh oleh masyarakat berasal dari dua jenis sumber yaitu sumur bor dan PDAM. Penggunaan air artesis banyak sekali diterapkan oleh masyarakat karena dapat menghemat listrik dan tidak dibatasi seperti penggunaan air PDAM. Pada pendistribusiannya penggunaan air dari sumur bor yang mengalirkan air dari sumber mata air ke rumah rumah penduduk membutuhkan alat penghubung berupa pipa. Pendistribusian ini sangat mempengaruhi pasokan air bersih kerumah rumah penduduk. Semakin berkembangnya penduduk maka semakin banyak rumah yang harus dialiri air bersih sehingga akan berdampak semakin berkurangnya jumlah pasokan air. Semakin jauh jarak rumah dengan sumber air atau semakin banyaknya cabang yang dilalui maka akan mempengaruhi jumlah pasokan air yang semakin kecil kerumah rumah penduduk karena akan banyak kemungkinan terjadinya kebocoran pipa dan semakin banyaknya salura pipa yang dibangun maka akan semakin mahal biaya pembangunan, pengembangan dan pemeliharaan infrastruktur air bersih menggunakan sumur bor. Permasalahan itu yang sering ditemui dibeberapa tempat didaerah jember kususnya daerah Jubung seperti yang terlihat pada gambar 1 denah peta pipa sumur bor .

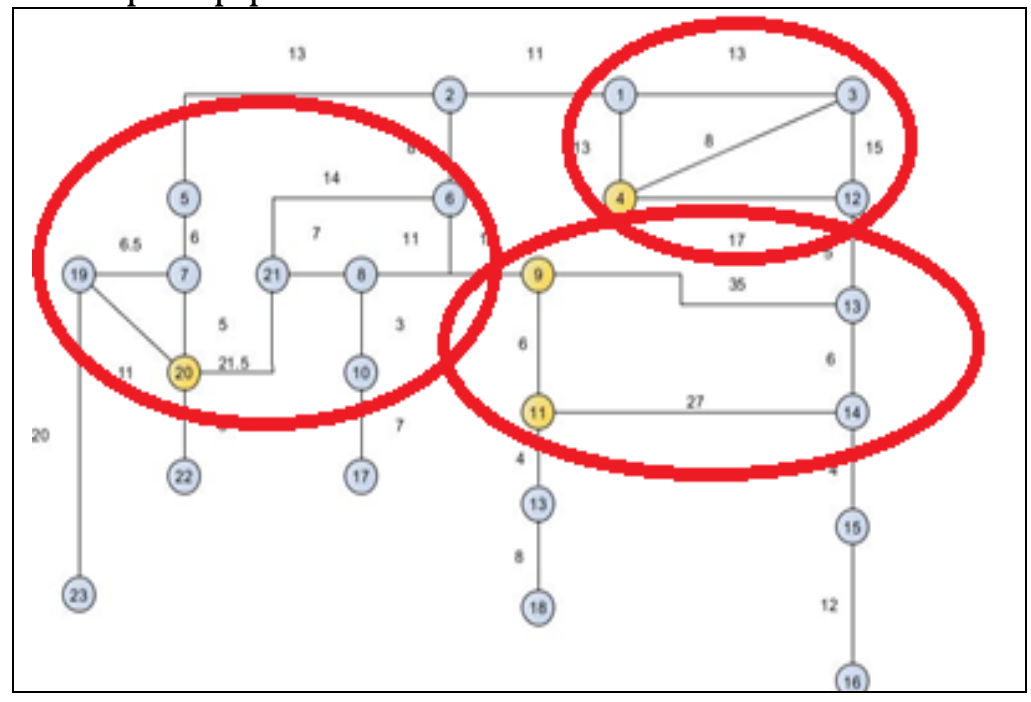

Gambar 1. Denah Peta Pipa Air Bor

Pada gambar satu terlihat ada 23 titik rumah penduduk yang terhubung dengan panjang 340 meter pipa penghubung. Pada gambar 1 terlihat bahwa banyak sekali rumah yang tersaluri air dari banyak saluran pipa akibat pengembangan pipa dari areal rumah penduduk baru, ada jalur yang memiliki banyak cabang dan ada yang sedikit cabangnya sehingga 
terjadi ketidakseimbangan saluran air bersih dari sumur bor. Permasalahan aliran air bersih dari sumur bor yang ada dijember ini maka dibutuhkan suatu penyelesaian berupa rekomendasi pengambilan keputusan pencarian jalur terpendek rute pipa air bersih. Pada penelitian ini menggunakan metode network yang merupakan salah satu metode dari riset operasi.

Riset operasi adalah salah satu bidang ilmu yang ada pada teknologi informasi untuk menyelesaikan permasalahan permasalahan yang ada diseputar produksi. Permasalahan yang diselesaikan adalah tentang optimasi produksi seperi mencari keuntungan yang besar atau penggunaan biaya minimal yang dikeluarkan untuk produksi terkait penggunaan sumber daya, optimasi permasalahan jaringan. Salah satu optimasi jaringan adalah mencari rute terpendek yang merupakan salah satu permasalahan di minimum Spanning Tree. Metode ini untuk menyelesaikan permasalahan dalam analisa jaringan untuk menentukan sisi atau busur yang menghubungkan antar simpul atau node secara efisien untuk memperoleh total minimum panjang sisi (atau busur). Pada metode ini tidak diperkenankan atau dihidarkan jalan berulang yang menyebabkan terjadinya looping atau siklus dari node satu ke node yang lain. Permasalahan ini banyak sekali mengimplementaskan teori graf dengan menggunakan salah satu algoritmanya adalah kruskal [4]. langkah langkah yang umum dilakukan pada permasalahan minimum Spanning Tree adalah memilih salah satu simpul sembarang yang memiliki bobot terkecil kemudian dihubungkan ke node terdekat atau terpendek berikutnya untuk dimasukkan kedalam satu kelompok setelah itu langkah langkah tersebut di ulang hingga semua node terhubung dan tanpa ada looping [3] Pada permasalahan dikehidupan sehari hari dapat diselesaikan dengan menggunakan logika matematika, salah satunya graf. graf dapat digunakan untuk merepresentasikan permasalahan dalam bentuk diskrit. graf merepresentasikan sebuah object dengan menggunakan bulatan atau node dan sisi sebagai penghubung antar node [4].

Pada penelitian sebelumnya tentang jaringan aliran air PDAM [5] membahas bahwa jaringan aliran air dapat direpresentasikan sebagai graf, dimana rumah sebagai verteks sedangkan pipa sebagai sisi [5]. Perbedaan dengan penelitian ini bobot sisi dilihat dari panjang pipa yang terhubung antar rumah dan sumber air sehingga tahapan awal adalah menganalisis biaya dari bentuk pipa panjang pipa dan banyak pipa yang digunakan untuk menyalurkan air sumur bor. Pada penelitian ini juga memperhatikan struktur tanah yang akan dilalui pipa dan hanya merekonstruksi pipa yang sudah ada tanpa membuat jalur pipa baru sehingga node dan sisi diperoleh dari denah. Ketika ada rute terpendek namun belum ada jalur pipa akhirnya ditiadakan karena kemungkinan tidak dilewati akibat dari kontur tanah yang tidak memungkinkan dilalui pipa.

Algoritma kruskal merupakan algoritma yang menitik beratkan pada bobot dari sisi bukan simpul sehingga cocok digunakan untuk kasus yang memiliki banyak simpul dari pada jumlah sisi dan semua simpul tidak saling 
terhubung dengan simpul lainnya atau graf tidak lengkap dengan kata lain algoritma kruskal digunakan untuk pencarian sisi dengan memberikan bobot disetiap sisi [1]. Pada kasus ini jumlah simpul lebih sedikit dari jumlah sisi namun setiap simpul ada yang tidak saling terhubung satu dengan yang lain, ada beberapa simpul yang tidak saling terhubung dengan simpul lainnya dan pada kasus ini menitik beratkan pada pencarian sisi karena sisi merepresentasikan pipa yang digunakan sehingga dipilihlah menggunakan algoritma kruskal.

\section{METODOLOGI PENELITIAN}

Pada peneltian ini menggunakan salah satu metode pada riset operasi yaitu metode jaringan. Tahap-tahap dalam Riset Operasi yaitu pembentukan model dengan mentransformasikan analisa situasi kedalam persamaan logika matematika. Tahapan yang dilalui adalah:

\section{a. Identifikasi analisa situasi}

Tahapan awal pada penelitian ini adalah identifikasi masalah melalui hasil analisa situasi. Kegiatan yang dilakukan adalah pengumpulan data berupa data primer dan sekunder. Data primer didapat dari hasil wawancara dan survey yang bertujuan memperoleh permasalahan kondisi lapangan secara nyata dan variabel yang mempengaruhi permasalahan tersebut. data data yang diperoleh adalah data peta jalur pipa sumur air bor dan data pipa jalur sumur bor. Data sekunder diperoleh melalui tahapan studi literatur untuk mengetahui metode yang digunakan dalam menyelesaikan masalah. Pada tahapan pengumpulan data ini diperoleh data untuk menentukan variabel keputusan dan tujuan.

1) Variabel keputusan pada penelitian ini adalah node dari rumah rumah penduduk yang dialiri sumur bor.

2) Tujuan (objective). Tujuannya adalah untuk menentukan jalur terpendek agar setiap rumah dialiri air dari sumur bor

3) Pembobotan pada penelitian ini adalah menggunakan jarak setiap titik rumah yang disebut dengan node dan biaya pipa yang dibutuhkan untuk menghubungkan setiap rumah.

\section{b. Pembentukan Model}

Pada penelitian ini pembentukan model menggunakan metode network yaitu pada permasalahan di Minimum Spanning Tree dengan algoritma kruskal.

\section{c. Mencari Penyelesaian Masalah}

Pada tahap ini implementasi algoritma kruskal untuk menentukan rute terpendek kemudian hasil dari analisa perhitungan tersebut digunakan sebagai alat untuk pengambilan keputusan. Pada tahapan penyelesaian permasalahan object direpresentasikan dalam bentuk graf. 
pada mencari pohon rentang minimum dari graf G dengan algoritma yang ditemukan Kruskal, mula-mula semua garis dalam G diurutkan berdasarkan bobotnya dari kecil ke besar. Kemudian pilih garis dengan bobot terkecil [3], tetapi tidak membentuk loop dengan garis-garis yang sudah dipilih terdahulu.

Misalkan $\mathrm{G}$ adalah graf mula-mula dengan $\mathrm{n}$ titik, $\mathrm{T}$ adalah Pohon Merentang Minimum E himpunan semua garis G. Secara formal, algoritma yang ditemukan Kruskal dapat dinyatakan sebagai berikut [6]:

1. Isi $T$ dengan semua titik-titik $G$ tanpa garis

2. $m=0$

3. Selama $\mathrm{m}<(\mathrm{n}-1)$ lakukan :

a. Tentukan garis e elemen E dengan bobot minimum. Jika ada beberapa e dengan sifat tersebut, pilih salah satu secara sembarang

b. Hapus e dari E

c. Jika e ditambahkan ke T tidak menghasilkan sirkuit, maka :

1) Tambahkan e ke $\mathrm{T}$

2) $m=m+1$

Tahapan berikutnya setelah penentuan rute terpendek adalah analisa hasil perhitungan untuk mengetahui perubahan panjang pipa dan perubahan biaya pemasangan pipa.

\section{HASIL DAN PEMBAHASAN}

a. Jalur Pipa Pendistribusian Air Bor tanpa Menggunakan Algoritma Kruskal

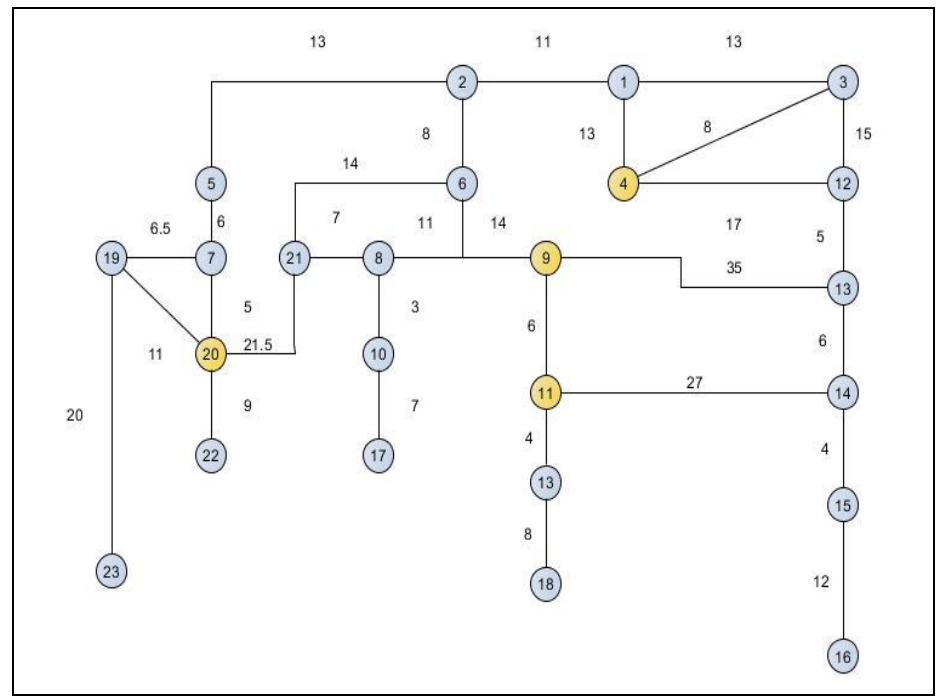

Gambar 2. Saluran pipa sumur bor awal

Pada gambar 2 merupakan saluran pipa sumur bor awal sesuai dengan analisis sitasi hasil wawancara dan survey terdapar 23 rumah dengan panjang 340 meter. Pada gambar 2 terlihat banyak beberapa titik rumah 
yang dilalui banyak saluran Dalam hal ini merupakan gambaran jalur pipa dalam pendistribusian air bor di daerah Jubung tanpa menggunakan algritma kruskal, yang awalnya pajang pipanya 340 meter. Pada gambar 2 terlihat banyak node yang dialiri banyak jalur seperti pada titik 20 terhubung dengan 4 titik yaitu titik $19,7,21,22$, selain itu ada titik titik yang terjadi perputaran (looping) yaitu titik 20, 4, 9, dan 11 yang ditandai dengan bulatan berwarna kuning. Hal itu menyebabkan pemborosan infratruktur pipa dan menyebabkan susahnya mendeteksi kerusakan pipa.

\section{b. Langkah - Langkah Pencarian Menggunakan Algoritma Kruskal}

Pada gambar 3 ini memberikan bobot pada tiap garis diantara dua node. Tahap berikutnya memilih garis dengan bobot yang paling minimum. Mencari panjang pipa yang paling pendek diantara pipa-pipa yang lain. Dan ditemukan pipa berukuran 3 meter diantara titik 8 dan 10 .

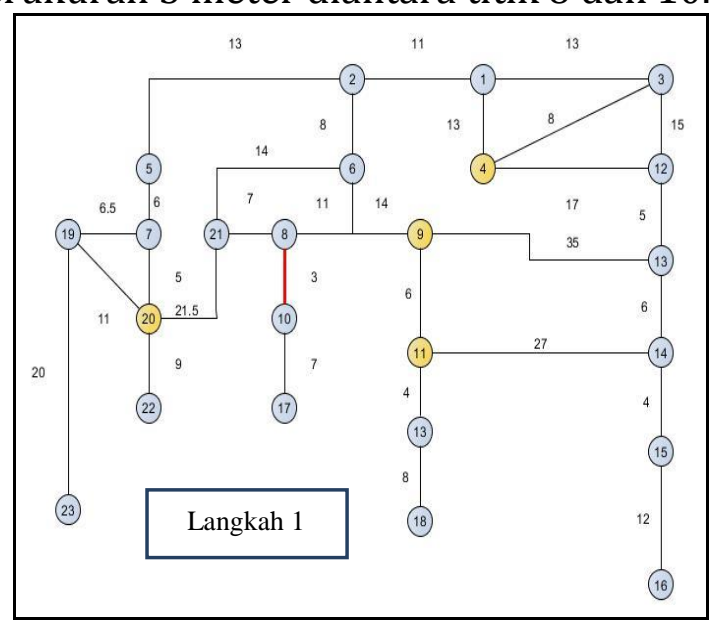

Gambar 3. Langkah awal algoritma kruskal

Tahap berikutnya adalah mencari dan tandai pipa yang ukurannya pendek dan lebih besar dari pipa pertama. Dan ditemukan pipa berukuran 4 meter. Pada gambar 4 lakukan cara yang sama pada langkah-langkah selanjutnya.

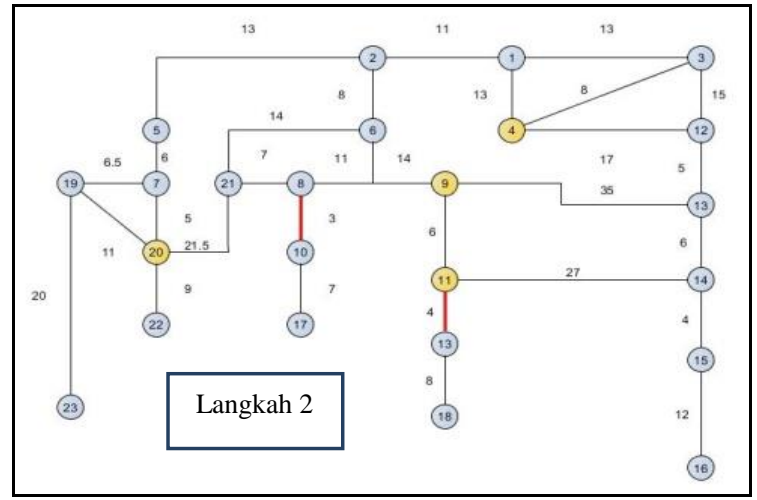

Gambar 4. Langkah kedua 
Jurnal Sains Komputer \& Informatika (J-SAKTI)

Volume (2) No.2 September 2018, pp. 121-129

ISSN:2548-9771/EISSN:2549-7200

http://tunasbangsa.ac.id/ejurnal/index.php/jsakti
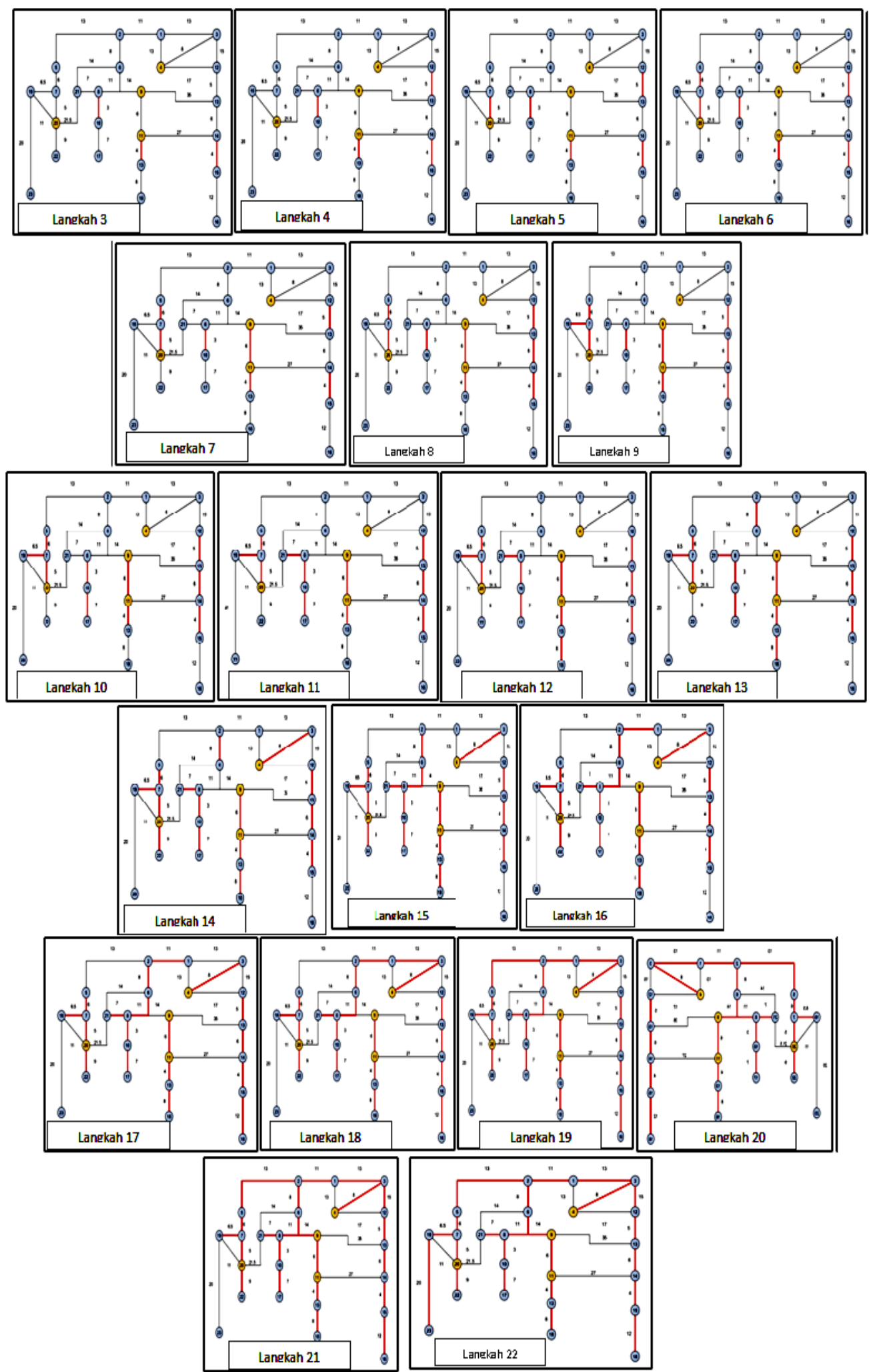

Gambar 5. Langkah keseluruhan dalam algoritma kruskal 
Pada gambar lima adalah pengurutan garis dari yang terkecil hingga yang terbesar sampai semua node terlewati sehingga membentuk seperti pohon. Pada tahap ini dipilih garis dengan bobot yang tidak memiliki kemungkinan terjadi looping atau perulangan atau perputaran seperti pada node 4,9,11,20. Pada gambar enam merupakan hasil dari algoritma kruskal. Pada gambar enam sudah tidak ada lagi sisi yang menyebabkan kemungkinan terjadinya looping atau perulangan. Ada beberapa sisi yang dibuang. Sisi yang dibuang adalah sisi yang menghubungkan node 1-4, 4-12, 19-20, 21-6. Dalam hal ini merupakan gambaran jalur pipa dalam pendistribusian air bor di daerah Jubung menggunakan algritma kruskal, yang hasilnya panjang pipa semakin minimum menjadi 201,5 meter.

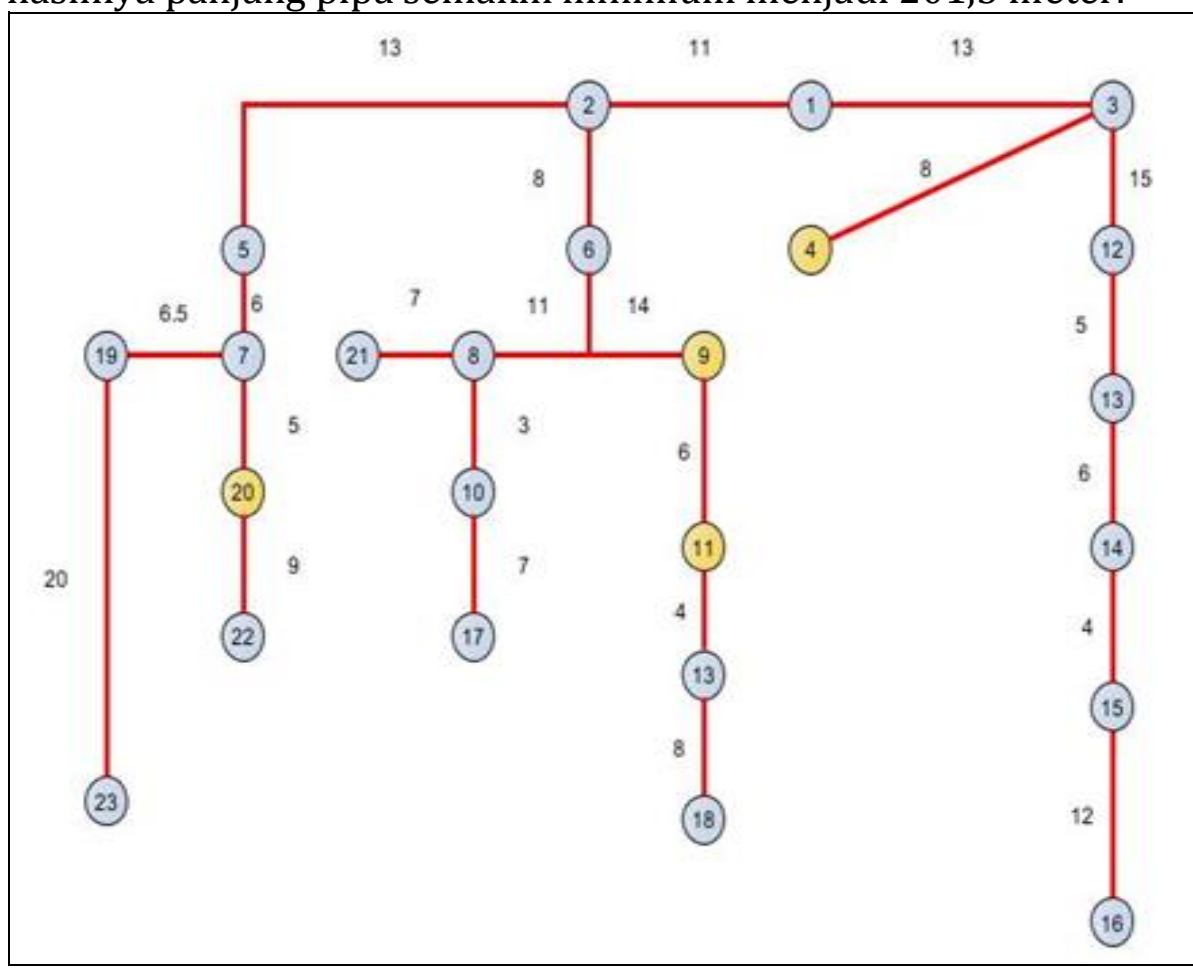

Gambar 6. peta denah pipa sumur bor setelah melalui perhitungan algoritma kruskal

Hasil implementasi pada algoritma kruskal adalah penggunaan pipa sebelum menggunakan algoritma kruskal adalah 11.936.500,- dan setelah menggunakan algoritma kruskal adalah Rp. 7.535.500,- sehingga dapat menghemat Rp. 4.401.000,-. Biaya ini dihitung dari panjangnya pipa dan banyaknya jenis pipa yang digunakan. Ada tiga jenis pipa yaitu pipa panjang, pipa tee dan pipa elbow.

\section{SIMPULAN}

Dalam penelitian ini dapat disimpulkan bahwa algoritma kruskal dapat memberikan solusi yang optimal dalam memecahkan sebuah masalah. Hal tersebut dapat ditunjukkan pada panjang pipa yang awalnya 340 meter 
menjadi 201,5 meter dan jumlah pipa dapat dihemat sebesar Rp. 4.401.000,-. Pada penelitian ini tidak diperhitungkan jumlah perbandingan jumlah sisi dan nodenya sehingga pada penelitian berikutnya dalam mengimplementasikan algoritma untuk menentukan rute terpendek dapat memperhatikan perbandingan jumlah sisi dan node atau simpul untuk memperoleh hasil yang lebih akurat.

\section{ACKNOWLEDMENT}

Penelitian ini merupakan hasil keluaran dari mata kuliah sistem operasi. Persembahan rasa terimakasih saya berikan kepada rekan satu tim pengampu mata kuliah sistem operasi dan mahasiswa mahasiswa saya yang telah menempuh mata kuliah ini, terutama Kharisma Ahmad P, Alifatur Rigasari, Risky Meidina, Anugraha Praysti I selaku tim surveyor pada paper ini.

\section{DAFTAR PUSTAKA}

[1] Hayu W., Yuliani, Dan Sam, M., "Pembentukan Pohon Merentang Minimum Dengan Algoritma Kruskal", Jurnal Scientific Pinisi, Volume 3, Nomor 2, , Hlm. 108-115, Oktober 2017

[2] Lufira, R. D., Suhardjono, S., Dan Marsudi, S., "Optimasi Dan Simulasi Sistem Penyediaan Jaringan Air Bersih Di Kecamatan Kademangan Kabupaten Blitar", Vol 3, No 1, Jurnal Pengairan, Http://Jurnalpengairan.Ub.Ac.Id, Universitas Brawijaya, Malang, 2012

[3] Nelfiyanti, Dan Dermawan D., "Penentuan Rute Distribusi Bbm Yang Optimal Menggunakan Metode Minimal Spanning Tree (Mst) Dan Algoritma Heuristik Di Pt.Telkomsel Area Kabupaten Pelalawan, Jurnal Teknik Industri - Universitas Hung Hatta, Vol. 1, No. 1, Halaman 58-69, Issn : 2302-0318, Juni 2012

[4] Sam M., Dan Yuliani, "Penerapan Algoritma Prim Untuk Membangun Pohon Merentang Minimum (Minimum Spanning Tree) Dalam Pengoptimalan Jaringan Transmisi Nasional Provinsi Sulawesi Selatan. Jurnal Dinamika", Vol. 07, No. 1, Halaman 50-61, Issn 2087 - 7889, April, 2016

[5] Wattimena A.Z, Dan Lawalata S., " Aplikasi Algoritma Kruskal Dalam Pengotimalan Panjang Pipa Kruskal Algorithm Application On Optimlaizing Pipes Network", Jurnal Barekeng, Vol. 7, No. 2, Hal. 13 18,2013

[6] Zakiah N, Desniarti, Samosir B.S. 2015. Minimum Spanning Tree Determination Program Using Kruskal Algorithm On Visual Basic 6.0. International Journal Of Science And Research (Ijsr),. Volume 4, Issue 12, ISSN (Online): 2319-7064, December, 2015. 